Review

\title{
Very High Resolution Optical Satellites: An Overview of the Most Commonly used
}

\author{
Pasquale Maglione \\ Department of Science and Technology, \\ University of Naples Parthenope, Centro Direzionale Is. C4, 80143, Naples, Italy
}

Article history

Received: 12-11-2015

Revised: 21-01-2016

Accepted: 22-01-2016

Email:

pasquale.maglione@uniparthenope.it

\begin{abstract}
Very High Resolution (VHR) satellite systems are platforms whose sensors acquire high geometric resolution images. Since 1972, when the first satellite was launched (Land sat ERTS), the spatial resolution of the satellite image has increased, making Ground Sample Distance (GSD) reaching $0.30 \mathrm{~m}$ at Nadir in panchromatic images. In this paper, after a brief introduction, concepts relative to orbits, types of sensors and resolutions are reported. Geostationary and sun-synchronous orbits are described; difference between push-broom and whisk-broom sensors are reported; the definition of the geometric, the radiometric and the temporal resolutions are listed. In the end, the characteristics of the most common VHR commercial optical satellite are mentioned: IKONOS-2, QuickBird-2, SPOT-5, GeoEye-1, WorldView-2 and WorlView-3 satellites.
\end{abstract}

Keywords: VHR Satellites, Optical Sensors, WorldView-3, Spatial Resolution, Radiometric Resolution, Orbits

\section{Introduction}

Commercial development in remote sensing has opened new possibilities for satellite imagery. In fact, in the late 1990s a new generation of high-performance sensors were launched in order to acquire two types of images: Multispectral and panchromatic. The former ones have a better spectral rather than a spatial resolution and they have a smaller band width. The panchromatic images have a larger band width and a higher geometric resolution. This new generation of sensors are able to take images with spatial resolution from 0.3 to $1 \mathrm{~m}$ in panchromatic mode and 2.5 to $4 \mathrm{~m}$ in multispectral one (Fritz, 1996). Very High Resolution (VHR) is the acronym distinguishing these satellites equipped with sensors that acquire with metric and sub-metric spatial resolution (Schreier and Dech, 2005).

In these years several experimentations have been carried out about the use at VHR images into geomatics applications. Tests were made to evaluate the use of the VHR images in order to generate middle scale and large scale mapping and for cover/land use identification $(\mathrm{Li}$, 1998; Samadzadegan et al., 2002; Chmiel et al., 2005; Abdelwahed et al., 2011; Fernàndez et al., 2014; Mostafa et al., 2014). Orthorectification is pivotal in these applications because it permits to ensure a consistent geometric relationship between points on the ground and their corresponding representation on the image
(Campbell and Wynne, 2011). Indeed, the terrain relief, the perspective and the motion of the sensor optics and the earth's curvature generate position errors on each image. Therefore, with orthorectification the image is made planimetric and terrain relief errors are corrected or reduced. Distinguishes two approaches for geometric correction applied to satellite images (Toutin, 2006): Rigorous (Bonneval, 1972; Wong, 1980) and synthetic models (Toutin, 2004; Tao and Hu, 2001; Dowman and Dolloff, 2000). In VHR satellite images orthorectification, synthetics models are widespread because, unlike the rigorous models, it is not necessary to know orbital parameters. Tests on several VHR images were conducted to validate the use of synthetics models $(\mathrm{Hu}$ and Tao, 2002; Amini and Hashemi, 2005; Errico et al., 2009; Maglione et al., 2013; Belfiore and Parente, 2014).

The increase of the number of spectral bands is another positive aspect linked to VHR satellite that permits a further improvement in classification. WorldView-2 multispectral sensor acquires on 8 bands in the visible range (Geoimage, 2015a). Coastal band, for example, travels farther into the water column without absorption and it is useful in the study of the seabed classification (Proteus, 2015). Coastal band, as well as Blue band and others, are used to define coastline by Normalize Difference Water Index (NDWI) (McFeeters, 1996), too (Basile Giannini et al., 2011; Maglione et al., 2014; 2015). 
Image Fusion methods (Van Genderen and Pohl, 1994), applied to VHR image, permit to obtain further improvements of the spatial resolution of multispectral images. In particular, pan-sharpening techniques allow to integrate the geometric detail of panchromatic data with the radiometric one of multispectral images (Zhang, 2004). Several applications about the use and the verify of pan sharpening techniques on VHR images were conducted in the last years (Zhou et al., 1998; Wang and Bovik, 2002; Tu et al., 2004; Aiazzi et al., 2007; Zhang, 2008; Kumar et al., 2009; Xin-Zhi et al., 2009; Shridhar and Alvarinho, 2013; Parente and Santamaria, 2014; Belfiore and Parente, 2015).

In Change Detection applications, the use of VHR images improves the thematic accuracy (Congalton, 2009) and permits of a better identification of the objects' contours. Maglione (2012), used IKONOS-2 and WorldView-2 images to detect new built by difference method. Pacifici et al. (2010) proposed a new approach based on Pulse-Coupled Networks (PCNNS) to evaluate the area of image where a significant change occurred. Dalla Mura et al. (2008) integrated the nonlinear and adaptive properties of the morphological filters with a Change Vector Analysis (CVA) applied to QuickBird images. Vettil (2012) described various urban change detection models using Quickbird and WorldView-2 images.

This paper is structured into two parts. In the first one were reported the general characteristics about satellite systems and sensors. The principal characteristics of the most common VHR satellite platform were considered in the second part. At the end, brief conclusions were reported.

\section{Satellite Systems}

\section{Brief History about Commercial Satellites}

The first license to build satellite that acquires high spatial resolution digital imagery in USA for commercial sale, was released to WorldView Inc. of Longmont (actually named DigitalGlobe) in 1993 (Kramer, 2002). The first commercial spaceborne that collects images with spatial resolution of $1 \mathrm{~m}$ in panchromatic mode using Charge Coupled Device (CCD) array was launched in 1999 from the Space Imaging Inc. of Thornton and named IKONOS-2 (Kramer, 2002). In 2001, Digital Globe Inc. launched QuickBird-2 satellite that acquires images with spatial resolution of $0.62 \mathrm{~m}$ in panchromatic mode (Kramer, 2002). WorldView-1 was the successor of QuickBird-2 and was launched from DigitalGlobe in 2007. It acquires panchromatic image with spatial resolution of $0.5 \mathrm{~m}$. In 2008, GeoEye Inc., launched GeoEye-1 satellite with a resolution of $0.41 \mathrm{~m}$ in panchromatic mode. In the last years, DigitalGlobe launched another two VHR satellite: WorldView-2 in 2009 and WorldView-3 in 2010. They have, respectively, 0.41 and $0.31 \mathrm{~m}$ as spatial resolution.

\section{Orbits}

Orbits characteristics are described in relation to the assumption that the Earth's gravitational field is spherical, for simplicity (Campbell, 2006). These types of orbits are called normal and they are ellipses with (Fig. 1): An Apogee (A), the point farthest from the Earth; a Perigee (P), the point closest to the earth; an Ascending Node (AN), the point where the satellite crosses the equator moving south to north; a Descending Node (DN), the point where the satellite crosses the equator passing north to south. The inclination of the orbit is defined in DN: The dihedral angle between the plane of the orbit and the equator one.

It is important to remember that the time required for a satellite to complete one orbit increases with the altitude.

Two principal grouping of satellites are recognized with reference to the types of orbit: Geostationary and sun-synchronous.

The former is a circular orbit that is located approximately at a distance of $35,800 \mathrm{~km}$ above the earth's equator; the satellite turns around the polar axis of the earth with the same direction and it moves on equatorial plane; the platform, in this way, has the same period of the earth and it is stationary with respect to the terrestrial surface observed (Grove, 1979; Montenbruck and Gill, 2000) Fig. 2. This type of orbit is frequently employed in communications and meteorology (Reeves, 1983).

Sun-synchronous orbit (Fig. 3) is obtained by the combination of orbital period and the inclination such that the satellite keeps pace with the sun's westward progress as the earth rotates; inclination is close to $90^{\circ}$, for this reason the orbit is called near-polar, indeed satellites pass near the north and south poles in each orbit (Lillesand et al., 2004). A satellite that moves along a sunsynchronous orbit acquires each part of the earth within its view at the same local sun time each day, so as to reduce variation in illumination during images acquisition (Campbell, 2006). The orbit altitude is about $700 \mathrm{~km}$.

The time that satellite spends to complete one orbit, called orbital period, is defined, in the case of a circular orbit, as (Elachi, 1987):

$$
T=2 \pi \cdot(R+h) \sqrt{\frac{R+h}{g_{s} \cdot R^{2}}}
$$

Where:

$T=$ The orbital period in sec

$R=$ The planet radius in $\mathrm{km}$ (about $6,380 \mathrm{~km}$ for the Earth)

$h=$ The orbit altitude in km evaluated from the surface of the Earth

$g_{s}=$ The gravitational acceleration at the Hearth's surface $\left(0.00981 \mathrm{~km} / \mathrm{sec}^{2}\right)$ 


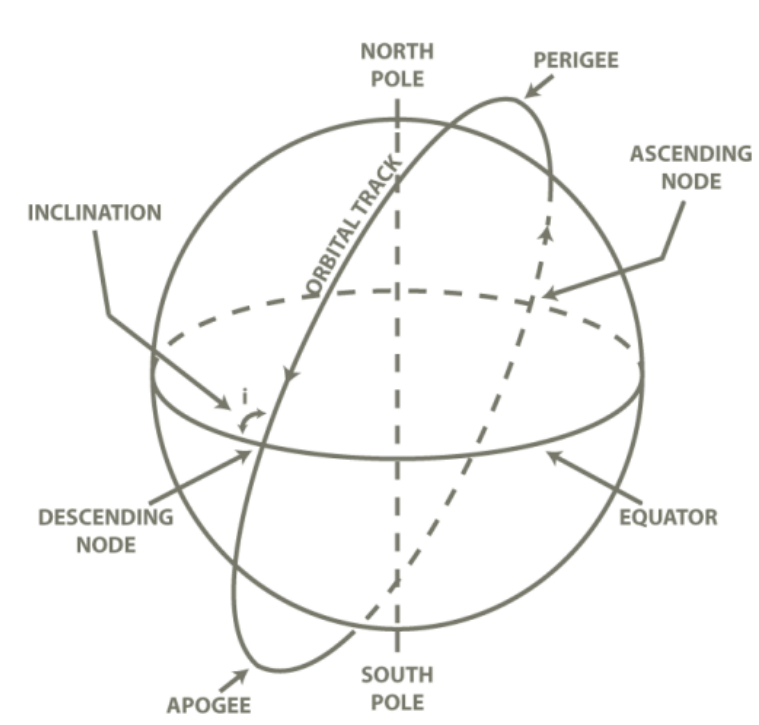

Fig. 1. Elliptical orbit: A schematic representation

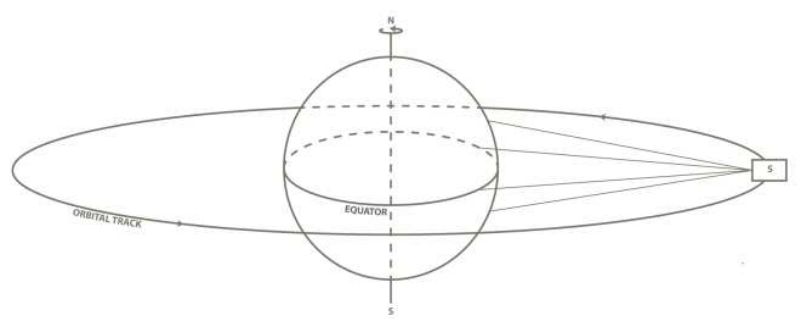

Fig. 2. Geostationary orbit: A schematic representation

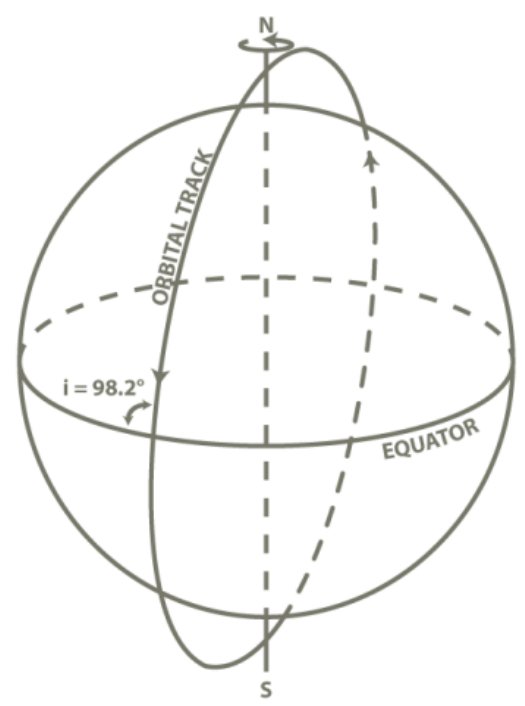

Fig. 3. An example of sun-synchronous orbit

\section{Types of Sensors}

VHR optical satellites described in this article have a push-broom sensor equipped with Charge Coupled Device (CCD) linear array detectors. Whisk-broom is another type of sensor that is mounted in the oldest satellite.

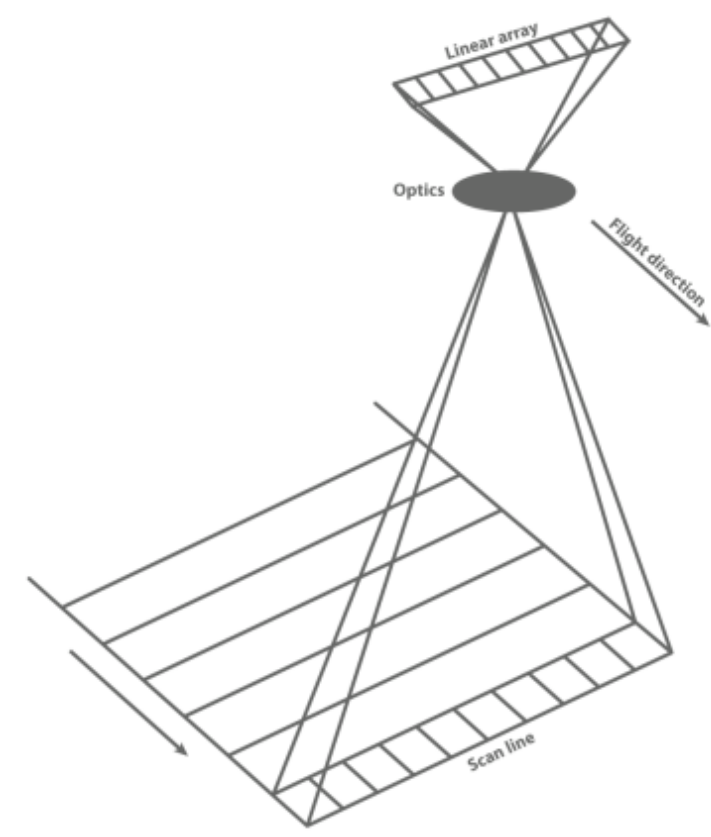

Fig. 4. Push-broom sensor: IKONOS-2

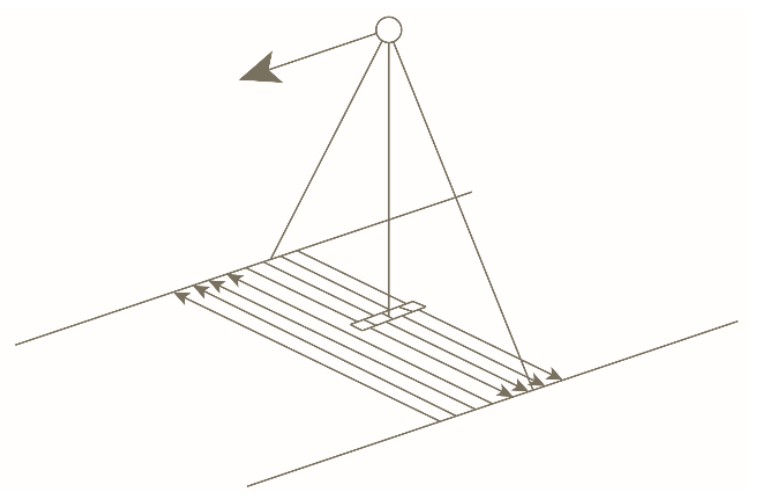

Fig. 5.Whisk-broom sensor: Landsat 7 ETM+

Push-broom (Shippert, 2013). A scanner with a line of detectors, called array, acquires in perpendicular to the flight direction of the spacecraft and the image is collected one line at a time; all the pixels in a line are acquired simultaneously (Fig. 4). Push-broom sensor is also called along track scanners.

Whisk-broom (Shippert, 2013). The sensor is a scanner. It uses a mirror to collect light onto a single detector. The detector moves back and forth and it acquires measurements from one pixel in the image at a time. Whisk-broom sensor is also called across track scanners (Fig. 5).

\section{Resolutions}

Four types of attributes are very important between sensors characteristics. They are referred to the capability to describe a scene in terms of: Geometrical detail, radiometric sensitivity, spectral content and temporal frequency of the acquisition (Brivio et al., 2006). 


\section{Geometric Resolution}

Rees (1999) defined geometric or spatial resolution as a measure of the smallest distance between two objects which can be distinguished by a sensor. It depends on both sensor characteristics and orbit height. In fact, from Fig. 6 it is possible to define spatial resolution " $\mathrm{D}$ " at nadir as:

$D=d \bullet h / f$

Where:

$d=$ Linear dimension of the single detector of sensor

$h=$ Height of sensor

$f=$ Focal length of the optical system

Height of sensor "h" can be considered constant when satellite platform is considered. In this case, geometric resolution is defined by Instantaneous Field of View (IFOV-Fig. 6): The cone angle within incident energy is focused on the detector (Lillesand et al., 2004). The projection on ground of IFOV is called Groundprojected Instantaneous Field of View (GIFOV) or Ground Sample Distance (GSD) (Miller et al., 2005). Field of View (FOV), on the other hand, is the full crosstrack angular coverage to which corresponds a ground projection called Ground-projected Field of View (GFOV) or Swath Width or footprint of the sensor (Schowengerdt, 2007).

\section{Radiometric Resolution}

Jensen defines it as the sensitivity of a sensor to difference in signal strength as it records the radiant flux reflected, emitted, or back-scattered from the terrain (Jensen, 2005). This sensitivity is measured as the intensity level and it is commonly defined by the number of bits used to quantize it (Gonzalez and Woods, 2008). Typical values of radiometric resolution are: 8,11 or 16 bits.

\section{Spectral Resolution}

Spectral resolution refers to the resolving power of a system in terms of wavelength (Kramer, 2002). It is determined by the bandwidth of the channel used (Reeves, 1983), where bandwidth is the spectral interval used to record brightness in relation to wavelength (Campbell, 2006). Panchromatic sensors acquire on a spectral bandwidth which is greater than the multispectral ones.

\section{Temporal Resolution}

The temporal resolution, in remote sensing, generally refers to how often the sensor records imagery of a particular area (Jensen, 2005). Sensors that acquire images with close intervals have a fine temporal resolution; in contrast, the ones with a long interval have a coarse resolution (Campbell, 2006).

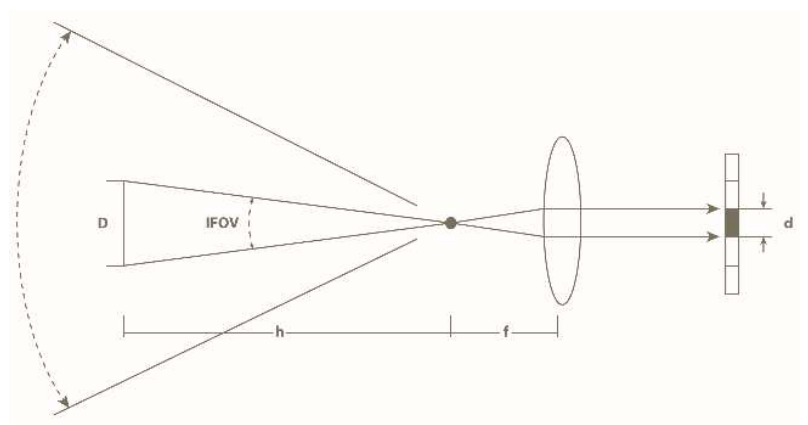

Fig. 6. Correlation among geometric resolution and height and characteristics of sensor: A graphic representation

\section{VHR Commercial Satellite}

\section{IKONOS-2}

IKONOS-2 was launched on September 1999 (DigitalGlobe, 2015a). The orbital altitude is $681 \mathrm{~km}$ and the orbital inclination is $98^{\circ} .1$. The swath is $11.3 \mathrm{~km}$, at nadir. The orbital period is $100 \mathrm{~min}$ and the revisiting one is about 3 days, that decreases to 1.5 days due to the possibility of tilting the push-broom sensor.

Panchromatic and multispectral images with radiometric resolution of 11 bits are acquired. The spectral interval for panchromatic image is $0.445-0.900$ $\mu \mathrm{m}$ (GeoEye, 2006) and spatial resolution is $0.82 \mathrm{~m}$ at nadir, resampled to $1 \mathrm{~m}$ for commercial scope (Geoimage, 2015b). Multispectral images (Fig. 7) are acquired in 4 bands: Blue $(0.445-0.516 \mu \mathrm{m})$; Green (0.506-0.595 $\mu \mathrm{m})$; Red (0.632-0.698 $\mu \mathrm{m})$; Near IR $(0.757-0.853 \mu \mathrm{m})($ GeoEye, 2006). Spatial resolution of this image is $3.2 \mathrm{~m}$ at nadir, resampled to $4 \mathrm{~m}$ for commercial scope. From January 2015, DigitalGlobe does not accept new IKONOS tasking order because the accuracy of satellite imagery does not meet product quality specification (SIC, 2015).

\section{QuickBird-2}

QuickBird-2 satellite was launched in October 2001. Initially, its orbital height was about $600 \mathrm{~km}$; after, DigitalGlobe opted for a fairly low orbital altitude of $450 \mathrm{~km}$ (ESA, 2000, 2015). In April 2011 the orbit satellite was raised to $482 \mathrm{~km}$ to give the spacecraft an extended life. In 2013, the altitude achieved was of 450 $\mathrm{km}$ (DigitalGlobe, 2015b). Currently, the satellite works at about $400 \mathrm{~km}$. The plane of the orbit has an inclination of $98^{\circ}$. The orbital period is $93.6 \mathrm{~min}$ at 450 $\mathrm{km}$ and $92.4 \mathrm{~min}$ at $400 \mathrm{~km}$; the revisit time varies from 2 to 12 days depending target location as the orbit decays; the swath, at nadir, is 16.8 at $450 \mathrm{~km}$ and 14.9 at $400 \mathrm{~km}$ (DigitalGlobe, 2015c).

Push-broom sensors acquire panchromatic and multispectral images. 


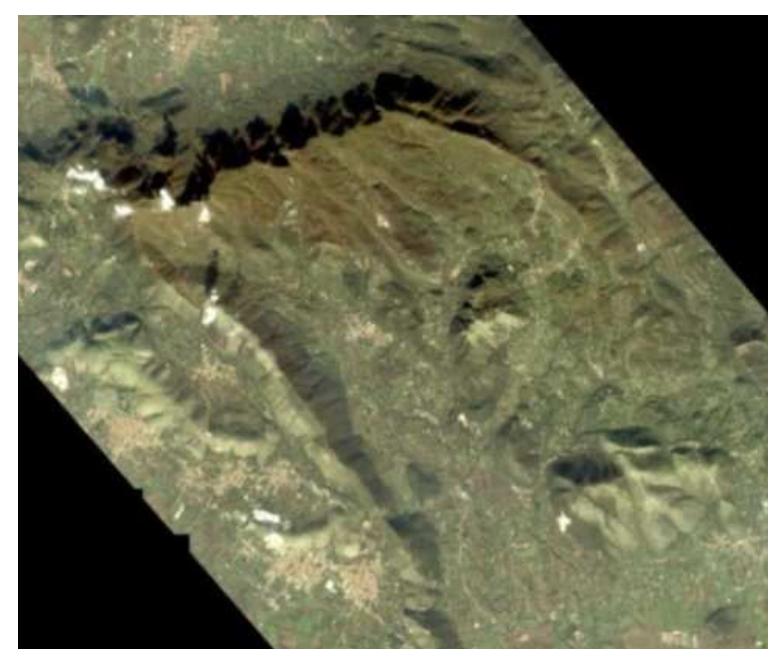

Fig. 7. IKONOS-2 image referred to an area of the Campania region ( $\mathrm{RGB}$ composition)

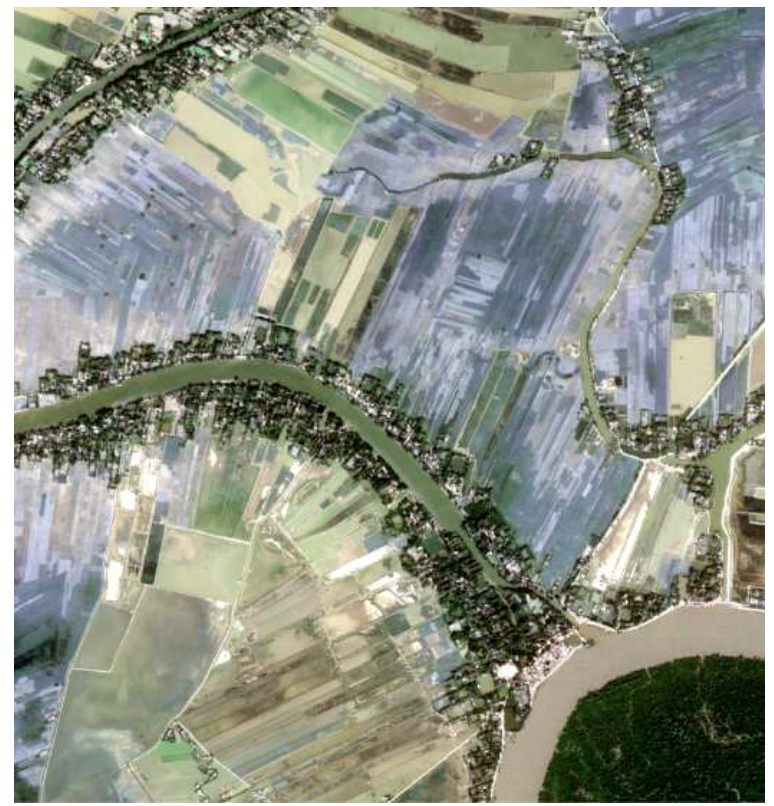

Fig. 8. QuickBird-2 image referred to Sundarbans, Bangladesh (RGB composition)

Spatial resolution at nadir is $0.55 \mathrm{~m}$ at $400 \mathrm{~km}$ and $0.61 \mathrm{~m}$ at $450 \mathrm{~km}$ for panchromatic image but both are resampled to $0.50 \mathrm{~m}$. For multispectral images, pixel size at nadir is $2.16 \mathrm{~m}$ at $400 \mathrm{~km}$ and $2.44 \mathrm{~m}$ at $450 \mathrm{~km}$, but both are upsampled to $2.5 \mathrm{~m}$ (DigitalGlobe, 2015c).

The spectral range is $0.405-1.053 \mu \mathrm{m}$ for the panchromatic images. The multispectral ones (Fig. 8) are acquired in: Blue $(0.430-0.545 \mu \mathrm{m})$; Green $(0.466-0.620$ $\mu \mathrm{m})$; Red (0.590-0.710 $\mu \mathrm{m})$; Near-IR (0.715-0.918 $\mu \mathrm{m})$.

Radiometric resolution for both panchromatic and multispectral images is 11 bits.

On Tuesday 27 January 2015, QuickBird-2 ended its mission and re-entered the earth's atmosphere at 01: 59 UTC (EIJ, 2015).

\section{SPOT-5}

Spot Image launched SPOT-5 satellite on 4 May 2002. The height of the orbit is $822 \mathrm{~km}$ and the orbital period is $101.4 \mathrm{~min}$; the revisited time is 26 days.

SPOT-5 satellite has two push-broom sensors: High Resolution Geometric (HRG) and HighResolution Stereoscopic (HRS). The former acquires both panchromatic and multispectral images; the latter only panchromatic images used to generate Digital Terrain Model (DTM) with geometrical resolution of $10 \mathrm{~m}$. The swath is $60 \mathrm{~km}$ for $\mathrm{HRG}$ and $120 \mathrm{~km}$ for HRS (ADS, 2015).

Spatial resolution for multispectral images (Fig. 9), acquired from HRG sensor, is $10 \mathrm{~m}$. Sensor returns the following bands: Green (0.500-0.590 $\mu \mathrm{m})$; Red (0.610$0.680 \mu \mathrm{m})$; Near-IR $(0.780-0.890 \mu \mathrm{m})$. SWIR band has a spectral range of $1.580-1.750 \mu \mathrm{m}$ and a spatial resolution of $20 \mathrm{~m}$ (ADS, 2015).

Spectral interval for the panchromatic images, acquired to $\mathrm{HRG}$, is $0.480-0.710 \mu \mathrm{m}$ and its spatial resolution is $5 \mathrm{~m}$ or $2.5 \mathrm{~m}$ in SUPERMODE modality: Two panchromatic images acquired simultaneously with spatial resolution of $5 \mathrm{~m}$ and an offset of half pixel in the focal plane are processed by interpolation processes (Guastaferro et al., 2012).

For all described images the radiometric resolution is 8 bits. In March 2015, SPOT-5 mission ended (ESA, 2015).

\section{GeoEye-1}

GeoEye-1 satellite was launched in September 2008. Its orbital height is $681 \mathrm{~km}$ and the plane of the orbit has an inclination of $98^{\circ}$. The orbital period is $98 \mathrm{~min}$ and the average revisited time is less than 3 days. The swath, at nadir, is $15.3 \mathrm{~km}$. The satellite has two push-broom sensors that acquire panchromatic and multispectral images (DigitalGlobe, 2015d).

Spatial resolution, at nadir, is: $0.41 \mathrm{~m}$ for panchromatic images, resampled to $0.50 \mathrm{~m}$ for commercial scope; $1.64 \mathrm{~m}$ for multispectral ones, upsampled to $2 \mathrm{~m}$ for commercial scope.

The band range is $0.450-0.800 \mu \mathrm{m}$ for panchromatic. Multispectral images (Fig. 10) are acquired in: Blue (0.450-0.510 $\mu \mathrm{m})$; Green (0.510-0.580 $\mu \mathrm{m})$; Red (0.655$0.690 \mu \mathrm{m})$; Near-IR $(0.780-0.920 \mu \mathrm{m})$.

Radiometric resolution for both panchromatic and multispectral images is 11 bits.

\section{WorldView-2}

WorldView-2 satellite was launched in October 2009 by DigitalGlobe (2015e). The orbit plane has an inclination of $97^{\circ} 0.2$ and satellite is placed at an altitude of $770 \mathrm{~km}$; the orbit period is $100 \mathrm{~min}$. The revisited frequency is 1.1 days at nadir and 3.7 days at $20^{\circ}$ offnadir. The swath width, at nadir, is $16.4 \mathrm{~km}$. 


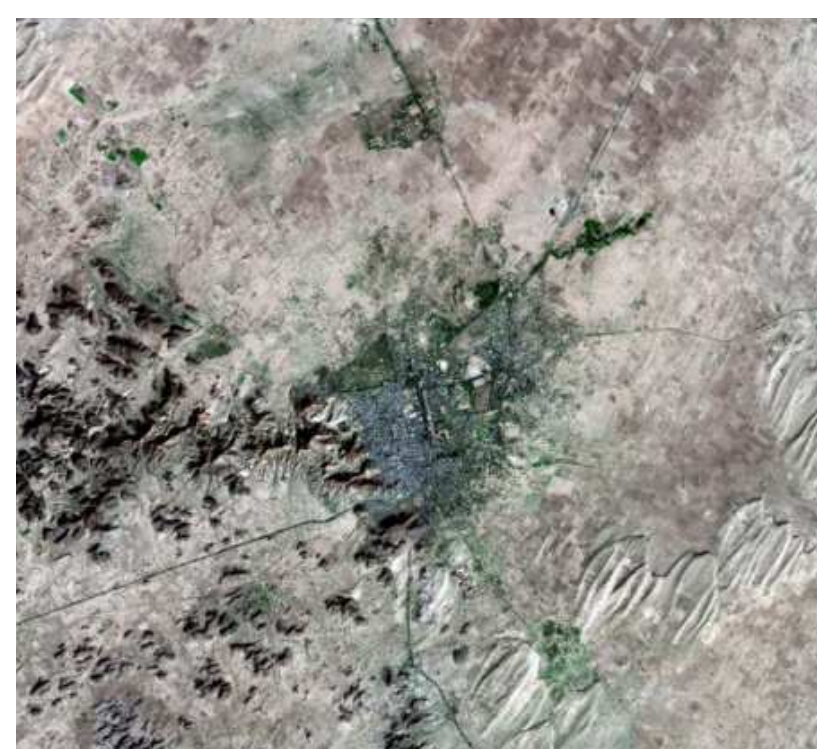

Fig. 9. SPOT-5 image referred to an area of the India (RGB composition)

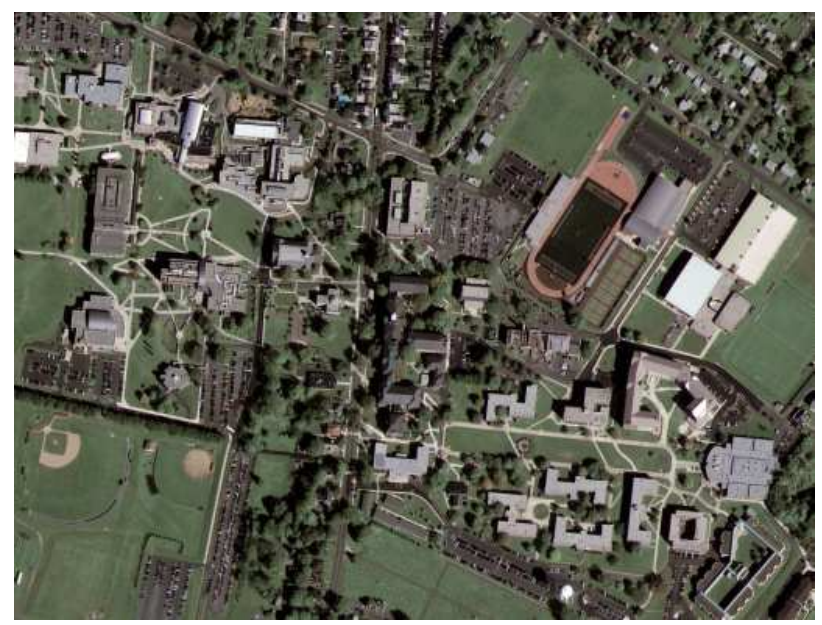

Fig. 10. GeoEye-1 image referred to Kutztown, Pennsylvania (RGB composition)

WorldView-2 satellite has two push-broom scanner that acquire: Panchromatic and multispectral images.

The former has a spatial resolution of $0.46 \mathrm{~m}$, resampled to $0.50 \mathrm{~m}$ for commercial scope; the spectral interval is $0.450-0.800 \mu \mathrm{m}$.

The multispectral images (Fig. 11) have a spatial resolution of $1.85 \mathrm{~m}$, resampled to $2 \mathrm{~m}$ for commercial scope. The sensor acquires 8 bands: Coastal (0.400$0.450 \mu \mathrm{m})$; Blue $(0.450-0.510 \mu \mathrm{m})$; Green $(0.510-0.580$ $\mu \mathrm{m})$; Yellow (0.585-0.625 $\mu \mathrm{m})$; Red (0.630-0.690 $\mu \mathrm{m})$; Red Edge (0.705-0.745 $\mu \mathrm{m})$; Near-IR1 (0.770-0.895 $\mu \mathrm{m})$; Near-IR2 (0.860-1.040 $\mu \mathrm{m})$.

Radiometric resolution is 11 bits for both panchromatic and multispectral images.

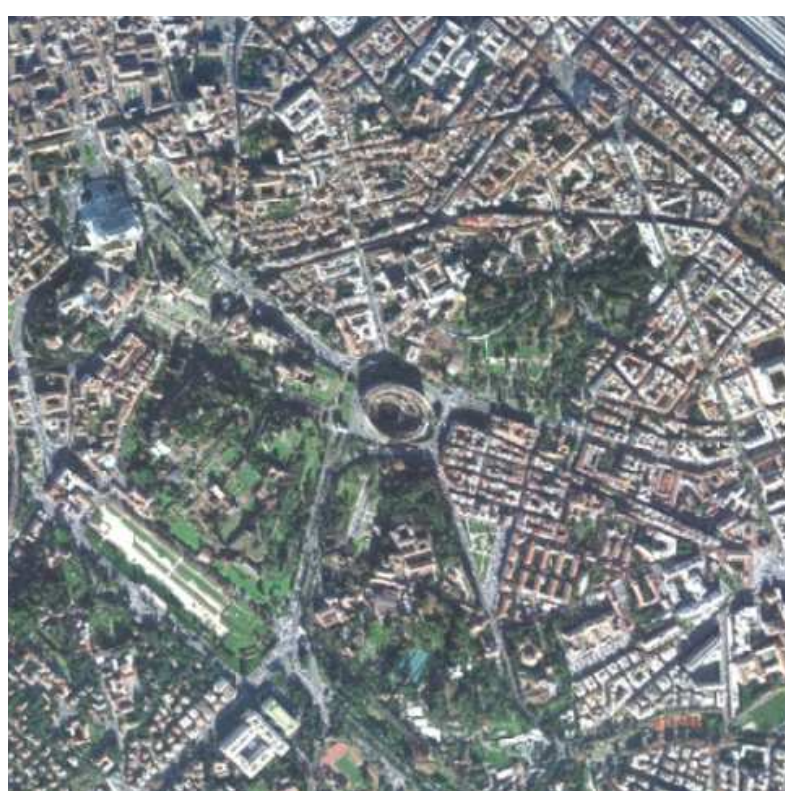

Fig. 11. WorldView-2 imagereferred to Rome (RGB composition)

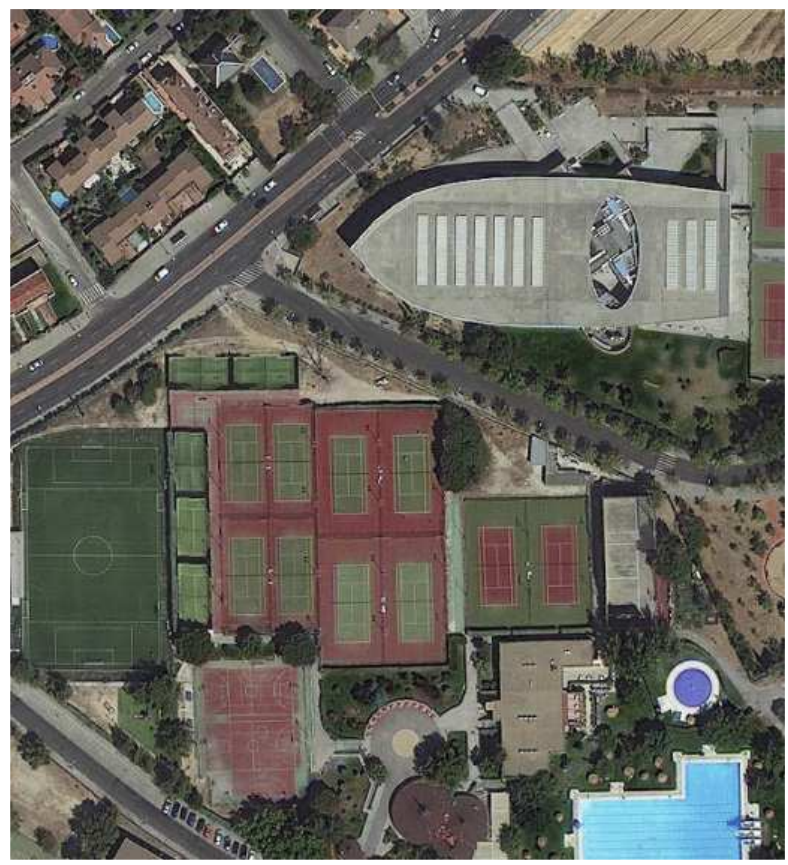

Fig. 12. WorldView-3 image referred to Madrid (RGB composition)

\section{WorldView-3}

It is a product of the DigitalGlobe and was launched in August 2014 (DigitalGlobe, 2015f). Its orbit has an inclination of $98^{\circ}$ and is placed at an altitude of $617 \mathrm{~km}$. The WorldView-3 satellite has an orbital period of $97 \mathrm{~min}$ and the revisited frequency is less than 1 day at nadir and 4.5 days at $20^{\circ}$ off-nadir. The swath, at nadir, is $13.1 \mathrm{~km}$. 
WorldView-3 satellite has two push-broom scanners that acquire panchromatic and multispectral images. It also mounts a CAVIS sensor.

Panchromatic images have a spatial resolution of $0.31 \mathrm{~m}$, resampled to $0.40 \mathrm{~m}$ for commercial scope; the spectral interval is $0.450-0.800 \mu \mathrm{m}$.

Multispectral images (Fig. 12) have a spatial resolution of $1.24 \mathrm{~m}$ in visible range, upsampled to $2 \mathrm{~m}$ for commercial scope and $3.70 \mathrm{~m}$ in SWIR bands. Eight bands, with radiometric resolution of 11 bits, are acquired: Coastal $(0.400-0.450 \mu \mathrm{m})$; Blue $(0.450-0.510$ $\mu \mathrm{m})$; Green (0.510-0.580 $\mu \mathrm{m})$; Yellow (0.585-0.625 $\mu \mathrm{m})$; Red (0.630-0.690 $\mu \mathrm{m})$; Red Edge (0.705-0.745 $\mu \mathrm{m})$; Near-IR1 (0.770-0.895 $\mu \mathrm{m})$; Near-IR2 (0.860$1.040 \mu \mathrm{m})$. In addition to this bands, it acquires another 8 band in SWIR: SWIR-1 (1.195-1.225 $\mu \mathrm{m})$; SWIR-2 (1.550-1.590 $\mu \mathrm{m})$; SWIR-3 (1.640-1.680 $\mu \mathrm{m})$; SWIR-4 (1.710-1.750 $\mu \mathrm{m})$; SWIR-5 (2.145-2.185 $\mu \mathrm{m})$; SWIR-6 (2.185-2.225 $\mu \mathrm{m})$; SWIR-7 (2.235-2.285 $\mu \mathrm{m})$; SWIR-8 $(2.295-2.365 \mu \mathrm{m})$. They have a radiometric resolution of 14 bits.

CAVIS sensor acquires 12 bands: Desert Clouds (0.405-0.420 $\mu \mathrm{m})$; Aerosol-1 (0.459-0.509 $\mu \mathrm{m})$; Green (0.525-0.585 $\mu \mathrm{m})$; Aerosol-2 (0.635-0.685 $\mu \mathrm{m})$; Water-1 (0.845-0.885 $\mu \mathrm{m})$; Water-2 (0.897-0.927 $\mu \mathrm{m})$; Water-3 (0.930-0.965 $\mu \mathrm{m})$; NDVI-SWIR (1.220-1.252 $\mu \mathrm{m})$; Cirrus (1.365-1.405 $\mu \mathrm{m})$; Snow (1.620-1.680 $\mu \mathrm{m})$; Aerosol-1 (2.105-2.245 $\mu \mathrm{m})$; Aerosol-2 (2.105-2.245 $\mu \mathrm{m})$.

\section{Conclusion}

The aim of this paper is to collect principal information about characteristics of the most popular VHR optical commercial satellite.

In the future, the evolution in aerospace technologies will open new frontiers in the field of remote sensing and its applications. For example, the increasing spatial resolution of the images allows for greater geometric detail in acquisitions and therefore an ever increasing ability of interpretation of the territory. Capacity that already today is particularly advanced, just consider that the size of the pixels of the image acquired by the satellite panchromatic WorldView-3 is $0.31 \times 0.31 \mathrm{~m}$.

\section{Acknowledgment}

Many thanks to the research group of Geomatics Laboratory of University of Naples "Parthenope".

\section{Funding Information}

The article was written in the context of the Research Projects of National Interest (PRIN)2010-2011"Innovative and emerging geomatics techniques of survey, remote sensing (by airplane, satellite, UAV) and WEBGIS for risk mapping in real time and the prevention of environmental damage" funded by MIUR (Ministerodell' Istruzione, dell'Università e dellaRicerca).

\section{Ethics}

The author has not conflicts of interest in the development and publication of this paper.

\section{References}

Abdelwahed, A.M., F.A. Farrag, A. Abdelhafiz and M.A. Besheer, 2011. Potential of using high resolution satellite images for mapping applications. J. Eng. Sci. Assiut. Univ., 39: 513-528.

Aiazzi, B., S. Baronti and M. Selva, 2007. Improving component substitution pansharpening through multivariate regression of $\mathrm{MS}+$ Pan data. IEEE Trans. Geosci. Remote Sensing, 45: 3230-3239. DOI: 10.1109/TGRS.2007.901007

ADS, 2015. Spot satellite technical data. Airbus Defence and Space.

Amini, J. and A.R.M. Hashemi, 2005. Geometric correction in Ikonos images-case study: Tehran, Iran. Proceedings of the Conference on From Pharaohs to Geoinformatics, Apr. 16-21, Cairo, Egypt, pp: 1-9.

Basile Giannini, M., P. Maglione, C. Parente and R. Santamaria, 2011. Cartography and remote sensing for coastal erosion analysis. Proceeding of the 2nd International Conference on Physical Coastal Processes, Management and Engineering. Coastal Processes, Apr. 27-29, Naples, Ital, pp: 1-12. DOI: $10.2495 / \mathrm{CP} 110061$

Belfiore, O.R. and C. Parente, 2014. Comparison of different methods to rectify IKONOS imagery without use of sensor viewing geometry. Am. J. Remote Sensing, 2: 15-19. DOI: $10.11648 /$ j.ajrs.20140203.11

Belfiore, O.R. and C. Parente, 2015. Orthorectification and pan-sharpening of worldview-2 satellite imagery to produce high resolution coloured orthophotos. Modern Applied Sci., 9: 122-130. DOI: 10.5539/mas.v9n9p122

Bonneval, H., 1972. Levéstopographiques par photogrammétrieaérienne, Photogrammétriegénérale, Tome 3, Eyrolles Editeur (Scientific collection of Institut Géographique National, Paris).

Brivio, P.A., G. Lechi and E. Zilioli, 2006. Principi e metodi di telerilevamento. CittàStudi, ISBN-10: 8825172931, pp: 525.

Campbell, J.B., 2006. Introduction to Remote Sensing. 4th Edn., Taylor and Francis, London, ISBN-10: 0415416884, pp: 626.

Campbell, J.B. and R.H. Wynne, 2011. Introduction to Remote Sensing. 5th Edn., Guilford Press, New York, ISBN-10: 160918176X, pp: 667. 
Chmiel, J., K. Lady-Druzycka, J. Pluto-Kossakowska, K. Osinska-Skotak and W. Wolniewicz et al., 2005. The evaluation of usability of VHR satellite images for land cover/land use identification in agricultural landscape. Proceedings of the Symposium on Global Developments in Environmental Earth Observation from Space, Jun. 6-11, Porto, Portugal, pp: 427-435.

Congalton, R.G., 2009. Assessing the Accuracy of Remotely Sensed Data: Principles and Practices. 2nd Edn., CRC Press/Taylor and Francis, Boca Raton, ISBN-10: 1420055127, pp: 183.

Dalla Mura, M., J.A. Benediktsson, F. Bovolo and L. Bruzzone, 2008. An unsupervised technique based on morphological filters for change detection in very high resolution images. Geosci. Remote Sensing Lett. IEEE, 5: 433-437. DOI: 10.1109/LGRS.2008.917726

DigitalGlobe, 2015a. IKONOS-2 datasheet.

DigitalGlobe, 2015b. Content collection.

DigitalGlobe, 2015c. QuickBird data sheet.

DigitalGlobe, 2015d. GeoEye-1 datasheet.

DigitalGlobe, 2015e. WorldView-2 datasheet.

DigitalGlobe, 2015 f. WorldView-3 datasheet.

Dowman, I. and J.T. Dolloff, 2000. An evaluation of rational functions for photogrammetric restitution. Int. Archives Photogrammetry Remote Sensing, 33: 254-266.

EIJ, 2015. QuickBird satellite ends its mission. Earth Imaging $\mathrm{J}$.

Elachi, C., 1987. Introduction to the Physics and Techniques of Remote Sensing. 1st Edn., Whiley, New York, ISBN-10: 0471848107, pp: 413.

Errico, A., P. Maglione, C. Parente and R. Santamaria, 2009. Geodetic datum transformation and cartographic re-projection of satellite images in GIS applications. Proceedings of the European Navigation Conference-Global Satellite System, May 3-6, Naples, Italy, pp: 1-9. DOI: 10.13140/2.1.4118.6566

ESA, 2000, 2015. QuickBird-2.

ESA, 2015. Spot-5.

Fernàndez, I., F.J. Aguilar, M.A. Aguilar and M.F. Alvarez, 2014. Influence of data source and training size on impervious surface areas classification using VHR satellite and aerial imagery through an objectbased approach. IEEE J. Selected Topics Applied Earth Observations Remote Sensing, 7: 4681-4691. DOI: $10.1109 /$ JSTARS.2014.2327159

Fritz, L.W., 1996. The era of commercial earth observation satellites. J. Am. Society Photogrammetry Remote Sensing, 62: 39-45.

GeoEye, 2006. IKONOS-Imagery products guide.

Geoimage, 2015a. The benefits of the eight spectral bands of WorldView-2.

Geoimage, http://www.geoimage.com.au/satellite/ikonos

Gonzalez, R.C. and Woods, R.E, 2008. Digital Image Processing. 3rd Edn., Prentice-Hall Inc, New Jersey, USA.
Grove, S., 1979. The geostationary orbit: Issues of law and policy. Am. J. Int. Law, 73: 444-461.

DOI: $10.2307 / 2201144$

Guastaferro, F., P. Maglione and C. Parente, 2012. Rectification of spot 5 satellite imagery for marine geographic information systems. Proceedings of the Advanced Research in Scientific Areas Virtual International Conference, Nov. 9-13, EDIS.

$\mathrm{Hu}, \mathrm{Y}$. and V. Tao, 2002. Updating solutions of the rational function model using additional control information. Photogrammetric Eng. Remote Sens., 68: $715-723$.

Jensen, J.R., 2005. Introductory Digital Image Processing: A Remote Sensing Perspective. 3rd Edn., Prentice Hall, Upper Saddle River, N.J., ISBN-10: 0131453610, pp: 526.

Kramer, H.J., 2002. Observation of the Earth and Its Environment: Survey of Missions and Sensors. 1st Edn., Springer Science and Business Media, Berlin, ISBN-10: 3540423885, pp: 1510.

Kumar, U., C. Mukhopadhyay and T.V. Ramachandra, 2009. Pixel based fusion using IKONOS imagery. Int. J. Recent Trends Eng., 1: 173-177.

Li, R., 1998. Potential of high resolution satellite imagery for national mapping products, Photogrammetric Eng. Remote Sensing, 64: 1165-1169.

Lillesand, T.M., R.W. Kiefer and J.W. Chipman, 2004. Remote Sensing and Image Interpretation. 5th Edn., John Wiley and Sons, Hoboken, NJ., ISBN-10: 0471152277, pp: 763.

Maglione, P., 2012. Techniques of data fusion and change detection, applied to remote sensing images, for the metrical analysis of territorial changes, University of Naples.

Maglione, P., C. Parente and A. Vallario, 2013. Using rational polynomial functions for rectification of GeoEye-1 imagery. IOSR J. Applied Geol. Geophys., 1: 12-17. DOI: 10.9790/0990-0161217

Maglione, P., C. Parente and A. Vallario, 2014. Coastline extraction using high resolution WorldView-2 satellite imagery. Eur. J. Remote Sens., 47: 685-699. DOI: 10.5721/EuJRS20144739

Maglione, P., C. Parente and A. Vallario, 2015. High resolution satellite images to reconstruct recent evolution of domitian coastline. Am. J. Applied Sci., 12: 506-515. DOI: 10.3844/ajassp.2015.506.515

McFeeters, S.K., 1996. The use of the Normalized Difference Water Index (NDWI) in the delineation of open water features. Int. J. Remote Sens., 17: 1425-1432. DOI: 10.1080/01431169608948714

Miller, R.L., C.E. Del Castillo and B.A. McKee, 2005. Remote Sensing of Coastal Aquatic Environments: In: Technologies, Techniques and Applications, Miller, R.L., C.E. Del Castillo and B.A. Mckee, (Eds.), Springer Netherlands. 
Montenbruck, O. and E. Gill, 2000. Satellite Orbits: Models, Methods and Applications. 1st Edn., Springer Science and Business Media, ISBN-10: 354067280X, pp: 369.

Mostafa, F.A., Y.G. Mostafa, M.A. Yousef and Y.A. Abas, 2014. Using of high resolution satellite images for updating large scale mapping in Egypt. J. Eng. Sci., 42: 1122-1137.

Pacifici, F. and F. Del Frate, 2010. Automatic change detection in very high resolution images with pulse-coupled neural networks. Geosci. Remote Sensing Lett. IEEE, 7: 58-62.

DOI: 10.1109/LGRS.2009.2021780

Parente, C. and R. Santamaria, 2014. Synthetic sensor of landsat 7 ETM+ imagery to compare and evaluate pansharpening methods. Sensors Trans., 177: 294-301.

Proteus, 2015. Developments and benefits of hydrographic surveying using multispectral imagery in the coastal zone.

Rees, G., 1999. The Remote Sensing Data Book. Cambridge University Press, New York, ISBN-10: 052148040X, pp: 262.

Reeves, R.G., 1983. Manual of Remote Sensing, Volume I. 2nd Edn., American Society of Photogrammetry, Falls Church, ISBN-10: 0937294411, pp: 2440.

Samadzadegan, F., A. Azizi, M. Sarpoulaki and A. Talebzadeh, 2002. Evaluation of the potential of the high resolution satellite imageries (IKONOS) for large scale map revision, Proceedings of the Symposium on Geospatial Theory, Processing and Applications, (TPA' 02), Ottawa, pp: 1-1.

SIC, 2015. IKONOS satellite sensor.

Shippert, P., 2013. Push broom and whisk broom sensors.

Schowengerdt, R.A., 2007. Remote Sensing. 3rd Edn., Academic Press, San Diego, CA.

Schreier, G. and S. Dech, 2005. High resolution earth observation satellites and services in the next decade-a European perspective. Acta Astronautica, 57: 520-533. DOI: 10.1016/j.actaastro.2005.03.029

Shridhar, D.J. and J.L. Alvarinho, 2013. A comprehensive evaluation of PAN-sharpening algorithms coupled with resampling methods for image synthesis of very high resolution remotely sensed satellite data. Adv. Remote Sens., 2: 332-344.

DOI: $10.4236 /$ ars.2013.24036

Tao, C.V. and Y. Hu, 2001. A comprehensive study of the rational function model for photogrammetric processing. Photogrammetric Eng. Remote Sens., 67: 1347-1357.
Toutin, T., 2004. Geometric processing of remote sensing images: Models, algorithms and methods. Int. J. Remote Sens., 25: 1893-1924. DOI: $10.1080 / 0143116031000101611$

Toutin, T., 2006. Comparison of 3D physical and empirical models for generating DSMs from stereo HR images. Photogrammetric Eng. Remote Sens., 72: 597-604. DOI: 10.14358/PERS.72.5.597

Tu, T.M., P.S. Huang, C.L. Hung and C.P. Chang, 2004. A fast intensity-hue-saturation fusion technique with spectral adjustment for IKONOS imagery. IEEE Trans. Geosci. Remote Sens., 1: 309-312. DOI: 10.1109/LGRS.2004.834804

Van Genderen, J.L. and C. Pohl, 1994. Image fusion: Issues, techniques and applications. Proceeding of the EARSeL Workshop on the Intelligent Image Fusion, Strasbourg.

Vettil, B.K., 2012. A comparative study of urban change detection techniques usinghigh spatial resolution images. Proceeding of the 4th GEOBIA, May 7-9, Rio de Janeiro, Brazil, pp: 1-8.

Wang, Z. and A.C. Bovik, 2002. A universal image quality index. Signal Process. Lett. IEEE, 9: 81-84. DOI: $10.1109 / 97.995823$

Wong, K.W., 1980. Basic Mathematics of Photogrammetry, in Manual of Photogrammetry. 4th Edn., America Society of Photogrammetry Publishers, Falls Church, pp: 101.

Xin-Zhi, L., W. Ping and Z. Yan-Bin, 2009. Application of SPOT 5 data fusion on investigating the ecological environment of mining area. Proceedings of the Urban Remote Sensing Event, May 20-22, IEEE Xplore Press, Shanghai, pp: 1-6. DOI: $10.1109 /$ URS.2009.5137594

Zhang, Y., 2004. Understanding image fusion. Photogrammetric Eng. Remote Sens., 6: 657-661.

Zhang, Y., 2008. Methods for image fusion quality assessment-a review, comparison and analysis. Int. Archives Photogrammetry Remote Sens. Spatial Inform. Sci., 37: 1101-1110.

Zhou, J., D.L. Civco and J.A. Silander, 1998. A wavelet transform method to merge Landsat TM and SPOT panchromatic data. Int. J. Remote Sens., 19: 743-757. DOI: $10.1080 / 014311698215973$ 